\title{
The Relationship Between Exposure to Terror Through the Media, Coping Strategies and Resources, and Distress and Secondary Traumatization
}

\author{
Hasida Ben-Zur, Sharon Gil, and Yinon Shamshins \\ University of Haifa
}

The study's main aim was to examine secondary traumatization among Israeli students. A sample of 203 university students in Israel, 41 men (20\%) and 162 women (80\%), aged 23.9 years on average, completed questionnaires on media exposure during terror attacks, posttraumatic and distress symptoms, coping styles, and personal resources of mastery and dispositional optimism. The main results showed that higher media exposure during terror attacks was related positively to higher levels of distress and posttraumatic symptoms. Higher resource levels were related to lower levels of posttraumatic symptoms, whereas greater use of avoidance coping was related to higher distress. These data suggest that the media, which tends to magnify and reinforce the effects of terror acts, can prompt secondary traumatization, and demonstrate the importance of an awareness of the risks of vicarious exposure to terror and trauma through the media.

Keywords: media exposure, terror acts, distress, resources, coping

Terrorism and related adverse acts became frequent phenomena toward the end of the 20th century and thereafter. Such acts of terrorism reflect violence emanating from political motives, usually aimed at civilians to create fear and coerce others into actions or inactions, and are perpetrated in acts that achieve maximum publicity (Bogen \& Jones, 2006). According to a statistical analysis of terrorist acts carried out between 1968 and 2004 based on the databases, the data for which were collected from open source materials, of the RAND Corporation and the Memorial Institute for the

Hasida Ben-Zur, Sharon Gil, and Yinon Shamshins, School of Social Work, University of Haifa, Haifa, Israel.

Correspondence concerning this article should be addressed to Prof. Hasida Ben-Zur, School of Social Work, University of Haifa, Mount Carmel, Haifa 31905, Israel. E-mail: zbz@netvision.net.il 
Prevention of Terrorism (Bogen \& Jones, 2006), 19,828 such events occurred, causing 86,568 injuries, of which 25,408 were fatal. Most of the acts involved the use of bombs and guns.

Terror acts are intended to cause harm, damage, and death among a large number of people, and are less predictable than natural disasters, as they tend to occur in places considered to be "safe" (Dougall, Hayward, \& Baum, 2005). As found for natural and man-made disasters, direct exposure to terrorist and other politically violent acts is associated with higher levels of posttraumatic stress disorder (PTSD) and other related distress and anxiety symptoms (e.g., Maguen, Papa, \& Litz, 2008; Norris et al., 2002).

Whereas a majority of the world's population is exposed to at least one traumatic episode during a lifetime (e.g., Bonanno, Galea, Bucciarelli, \& Vlahov, 2006; Galea, Nandy, \& Vlahov, 2005), and tens of thousands of people are affected by terror acts directly, many more are affected indirectly, namely, family members, friends, rescue workers, or residents living in the vicinity of the terrorist attacks (see Thompson et al., 2006). Another key factor in the spread of the effects of terrorism and political violence is the mass media, which act as conduits in affecting the general public. Terrorists thus attract the attention of the news media, mainly TV and the Internet, and through these media, that of the public and government, both in the target country and around the globe (Nacos, 2007).

\section{Secondary Traumatization and Media Exposure}

Various terms have been used to describe the pathological consequences of indirect exposure to trauma, including secondary traumatization, compassion fatigue (Figley, 1995), and vicarious traumatization (McCann \& Pearlman, 1990). Although they differ in phenomenology and manifestations, all of these terms essentially describe the negative impact of bonding to a trauma victim and exposure to that victim's traumatic material (McCann \& Pearlman, 1990; Pearlman \& Saakvitne, 1995).

The symptoms characterizing secondary traumatization include reexperiencing the traumatic event through intrusive thoughts, images, flashbacks, or dreams; avoidance of reminders of the trauma, and general numbing; and psychological and physiological hyper-arousal symptoms, such as alert reactions, general anxiety, and increased heart rates. These symptoms have been found to be similar to those of PTSD, but of a lower intensity. Another indirect effect, in addition to secondary or vicarious trauma caused by proximity to a terror victim, is that prompted by watching and learning about the effects of terror acts and political violence from the mass media (Dougall et al., 2005), which reach millions of people. The mass media include all 
methods or channels of information transfer and entertainment, namely TV, Internet, radio, cell phones, and newspapers (Wilkinson, 1997; Swenson \& Johnson, 2003). Thus, it is highly probable that watching TV or searching the Internet will lead to exposure to the outcomes of terror acts both visually and in terms of verbal information and commentary. Indeed, Schuster et al. (2001) conducted a national survey after the 9/11 terror attacks and reported that $44 \%$ of TV viewers developed one or more of the secondary PTSD symptoms, and Swenson and Johnson (2003) found that in an American academic population, $76 \%$ of respondents reported one or more symptoms of secondary PTSD, and 32\% reported three or more such symptoms. Among students, media exposure (hours spent on TV viewing the 9/11 coverage) was related to PTSD symptoms (Collimore, McCabe, Carleton, \& Asmundson, 2008). In sum, the effects of the media are associated with high levels of posttraumatic symptoms, acute distress, and feelings of insecurity and vulnerability (Slone, Shoshani, \& Baumgarten-Katz, 2008). The present study aimed to assess coping styles and resources as moderators of the media traumatic effects.

\section{Coping Strategies, Styles, and Resources}

Coping represents behavioral and cognitive efforts to deal with stressful encounters (e.g., Lazarus, 1999; Lazarus \& Folkman, 1984; Terry, 1994). Lazarus and Folkman (1984) and Lazarus (1999) classified coping modes as either problem-focused or emotion-focused, thereby delineating the function of coping as dealing mainly with the problem, or with its emotional and physiological outcomes, respectively. Another distinction is approachavoidance, which refers to engaged coping strategies whose goal is to reduce, eliminate, or manage the problem, versus disengaged coping whose goal is to ignore or avoid the problem and its emotional consequences (Skinner, Edge, Altman, \& Sherwood, 2003; Nes \& Segerstrom, 2006). The coping model adopted for the present research is that of Carver, Scheier, and Weintraub (1989) which is based on the Lazarus cognitive model of stress (e.g., Lazarus \& Folkman, 1984) and behavioral self-regulation theory (Carver \& Scheier, 2000). This coping framework includes 15 coping strategies classified by three types: problem-focused strategies, which are considered effective and adaptive; and two different kinds of emotion-focused strategies-those considered functional and sometimes helpful in solving the problem, and those considered ineffective and dysfunctional.

Coping is found to be correlated with outcomes in specific contexts: Emotion-focused coping is highly correlated with psychological distress (e.g., Ben-Zur, Gilbar, \& Lev, 2001; Carver \& Scheier, 1993; Zeidner, 1995, 
2007; Zeidner \& Ben-Zur, 1993). Problem-focused strategies show either no significant correlations with state-anxiety (e.g., Zeidner \& Ben-Zur, 1993), or positive associations (Zeidner, 2007), although they are found to be related to better performance (Baggett, Saab, \& Carver, 1996; Zeidner, 1995). A meta-analysis showed that emotion-focused coping is highly related to distress and its variants (e.g., depression), but problem-focused coping associations with distress were much weaker and inconsistent in direction (Penley, Tomaka, \& Wiebe, 2002). In contrast, recent research on coping with traumatic events, summarized by Maguen, Papa, and Litz (2008), suggests that the results regarding coping with traumatic events such as terrorism, which is not under the individual's control, are equivocal. Thus, several studies found emotion-focused coping to be related to higher levels of distress, anxiety, or PTSD following terror attacks (e.g., Gil \& Caspi, 2006; Liverant, Hofmann, \& Litz, 2004), and other studies in the context of political violence in Israel found problem-focused coping to be related to higher levels of anxiety (e.g., Gidron, Gal, \& Zahavi, 1999).

The present study conceptualized coping as a stable cognitive and behavioral characteristic of the individual, following other investigators who used a trait approach in regard to coping (e.g., Carver et al., 1989; Krohne, 1993; Miller, Combs, \& Kruus, 1993). Very few studies, however, have dealt with the association of coping styles with distress and PTSD. Ben-Zur and Zeidner (1995) reported the everyday use of emotion-focused coping associations with anxiety following the Gulf War of 1991, and Ben-Zur (2002b) showed positive associations between dispositional problem/accommodation coping and positive affect, as well as between avoidance/disengagement coping and negative affect.

Apart from coping, personal traits have also been recognized as an important determinant of coping and distress when individuals encounter stressful events. Such traits as dispositional optimism and locus of control or mastery are considered to be personal resources that have been accorded a central role in all contemporary models of stress (Hobfoll, 1989, 1991, 2001; Lazarus \& Folkman, 1984; Moos \& Schaefer, 1993; Pearlin, 1999). Dispositional optimism is often defined as the generalized expectancy that good outcomes will occur when confronting major problems (Scheier \& Carver, 1985). This personal quality is considered to be a determinant of sustained efforts to deal with problems, in contrast to turning away and giving up. Most research findings in this area indicate a positive association between optimism and coping with stressful life events such as chronic diseases or disability (e.g., Ben-Zur \& Debi, 2005; Epping-Jordan et al., 1999; Scheier $\&$ Carver, 1992). Mastery refers to the extent to which a person perceives having control over his or her life events (Pearlin \& Schooler, 1978). It is also defined as inner feelings of strength and as the capacity to cope with and overcome obstacles by relying on one's own efforts (Hobfoll, Jackson, 
Hobfoll, Pierce, \& Young, 2002). Studies have indicated that mastery is strongly associated with lower levels of anger and depressive moods (e.g., Ennis, Hobfoll, \& Schroder, 2000), or negative affect (Ben-Zur, 2002b) and with higher levels of positive affect (Ben-Zur, 2002b, 2003). Finally, a composite score of optimism, perceived control, and self-esteem was related to preabortion stress appraisals and predicted positive wellbeing following the abortion (Major, Richards, Cooper, Cozzarelli, \& Zubek, 1998); it also predicted positive adjustment to heart disease (Helgeson, 1999), and lower posttraumatic symptoms among uprooted Israeli citizens (Ben-Zur, 2008).

In studies of natural and man-made disasters (Norris et al., 2002), high levels of personal resources were found to be related to lower distress and lower posttraumatic stress, whereas resource loss was found to be related to high posttraumatic stress levels. High postdisaster distress levels were related to lower optimism following a hurricane (Benight, Swift, Sanger, Smith, \& Zeppelin, 1999), whereas a study of the effects of personal resources following an earthquake (Sumer, Karanci, Berument, \& Gunes, 2005) reported higher levels of optimism and perceived mastery to be related to lower distress and intrusions.

\section{The Israeli Context}

Israeli citizens have been living with wars, political violence, and acts of terror since the country's existence as an independent state. Since 2000 alone, such events have included the second major uprising of the Palestinians living under Israeli occupation - the Al-Aksa Intifada - which started in 2000, which was marked by suicide bombings and terrorist attacks throughout Israel, and which lasted for about five years, with hundreds of Israelis killed and thousands wounded during that period; the systematic bombardment of the town of Sderot and other settlements in southern Israel bordering the Gaza Strip by missiles launched from the strip over a period of seven years; and the second Lebanese war in the summer of 2006, which witnessed a steady bombardment of missiles launched by Hizballah into northern Israel.

Studies conducted in Israel have investigated the psychological outcomes of terror attacks during the intifada (e.g., Gelkopf, Solomon, Berger, \& Bleich, 2008), missile attacks on the Israeli Southern settlements (e.g., Gelkopf, Berger, Bleich \& Silver, in press), and missile attacks during the second Lebanese war (e.g., Ben-Zur \& Almog, in press; Palmieri, CanettiNisim, Galea, Johnson, \& Hobfoll, 2008). These studies indicate that direct exposure to acts of violence and terror resulted in high levels of PTSD, posttraumatic symptoms, and/or depression and anxiety.

All of these events were covered by the media intensively, especially by TV. Thus, although most of the population in Israel did not experience terror 
acts directly, almost all experienced these acts vicariously through the media. Several studies conducted in Israel have shown associations between media coverage of terror acts and high levels of anxiety (Slone, 2000; Slone \& Shoshani, 2010) or secondary trauma symptoms (Keinan, Sadeh, \& Rosen, 2003). One of the important questions in this context is how Israeli people are affected by the media and how they cope with the direct and indirect effects of terror acts.

\section{Study Aims and Hypotheses}

The study aimed to assess secondary posttraumatic symptoms among university students, a population that makes extensive use of the media, and especially of Internet news coverage and short message service (SMS) messaging (Teo \& Heong Pok, 2003). The study used coping strategies and resources, as well as level of exposure to terror acts directly and through the media, as the main variables that can potentially affect posttraumatic symptoms and distress. The hypotheses were:

H1: High levels of media exposure will be associated with high levels of posttraumatic symptoms and distress.

H2: High levels of emotion-focused coping and avoidance will be associated with high levels of posttraumatic symptoms and distress.

H3: High levels of problem-focused coping will be associated with low levels of posttraumatic symptoms and distress.

H4: High levels of personal resources will be associated with low levels of posttraumatic symptoms and distress.

H5: High levels of direct exposure to terror acts will be associated with high levels of posttraumatic symptoms and distress.

\section{METHOD}

\section{Sample and Procedure}

The sample consisted of 203 undergraduate students (who agreed to participate out of 241 students approached; $84 \%$ ) at a university in northern Israel. The sample contained 41 men (20\%) and 162 women (80\%), mean age 
$23.9(S D=3.86$, range $19-42)$, the majority born in Israel $(73.4 \%)$, served in the Israeli army (76.8\%), were Jewish (85.7\%), and secular (77.3\%). The mean reported economic status was about average $(3.09, S D=0.95$; range $1=$ bad; $6=$ excellent). The students were approached in classes, and their participation was voluntary. The general aim of the study was described in the instructions, and the questionnaires were completed in class and handed to the authors. The data were coded and analyzed anonymously. The research was approved by the University of Haifa internal review board.

\section{Instruments}

Table 1 presents the psychometric properties of the study variables.

\section{Demographic Details}

These consisted of age, gender, sector (Jewish or Arab), marital status, place of birth, level of religiosity, military service, number of siblings, parents' education, and economic status as assessed by respondent.

\section{Mastery (Pearlin \& Schooler, 1978)}

The scale measures perception of personal control over life outcomes (e.g., "I can do just about anything I really set my mind to do") and contains seven items rated on a 1 (not at all characteristic of me) to 7 (very characteristic of me) scale. The two high-mastery items and the five reversecoded items are averaged, with a high score indicating a high level of

Table 1. Psychometric Properties of the Research Variables

\begin{tabular}{lccc}
\hline \multicolumn{1}{c}{ Variable } & $M$ & $S D$ & $\alpha$ \\
\hline Mastery & 5.05 & 1.01 & .80 \\
Optimism & 3.66 & 0.73 & .81 \\
Problem-focused coping & 2.18 & 0.44 & .65 \\
Emotion/support coping & 2.05 & 0.54 & .64 \\
Avoidance coping & 0.84 & 0.43 & .58 \\
Media-terror & 3.48 & 0.67 & .56 \\
Media-updating & 3.49 & 0.62 & .54 \\
Media-leisure & 3.29 & 0.71 & .57 \\
PSS-SR & 0.41 & 0.42 & .89 \\
BSI & 0.91 & 0.76 & .94 \\
\hline
\end{tabular}

Note. $\quad$ PSS-SR = Post-Traumatic Stress Symptoms-Self-Report; BSI = Brief Symptom Inventory. 
mastery. Hobfoll and Walfisch (1984) reported a test-retest reliability of .85 or above for the scale, with reasonable internal reliability levels $(\alpha=.75)$. The Hebrew form showed satisfactory internal reliability levels in Israeli studies (e.g., Ben-Zur, 2002a, 2002b, 2003; $\alpha=.69-.80$ ) and in the present study $(\alpha=.80)$.

\section{Dispositional Optimism (Life Orientation Test LOT; Scheier and Carver, 1985)}

This scale assesses stable positive outcome expectancy, and consists of eight items (e.g., "In uncertain times, I usually expect the best"), rated on a 1-5 $(1=$ disagree to a large extent; $5=$ agree to a large extent $)$ scale. The four positively worded and four reverse-coded items are averaged, with a high score indicating an optimistic tendency. The internal reliability and test-retest of the original version were satisfactory $(\alpha=.76$, test-retest $=$ .79; Scheier \& Carver, 1985). The Hebrew version (Zeidner \& Ben-Zur, 1994) has been used in various Israeli studies, and showed satisfactory reliabilities (e.g., Ben-Zur \& Debi, 2005, $\alpha=$.76; Ben-Zur, 2003, $\alpha=$ $.61-.83$; in the present study, $\alpha=.81$ ).

\section{COPE Scale (Carver et al., 1989)}

The use of coping strategies to deal with stressful events in everyday life was tested by the short Hebrew version of the COPE scale (Zeidner \& Ben-Zur, 1994), which contains 15 coping strategies, each represented by the sum of two items. Respondents indicated the extent to which each of the 15 strategies was used in general. Responses were rated on a four-point scale ranging from $0=$ not at all to $3=$ great extent. The strategies were active coping, planning, seeking instrumental social support, seeking emotional social support, suppression of competing activities, religion, positive reinterpretation and growth, restraint coping, acceptance, ventilation of emotion, denial, mental disengagement, behavioral disengagement, alcohol/drug use, and humor. Following Carver et al.'s (1989) exploratory factor analysis with varimax rotation was applied to the 15 coping-strategy scores yielding five factors. The first three factors were compatible with Carver et al.'s (1989) factor analysis outcomes, and were used in this study to construct three coping subscales: problem-focused coping (including active coping, planning and suppression, accounting for $13 \%$ of the common factor variance); two scales of emotion-focused coping: avoidance coping (including behavioral and mental disengagement, denial, and alcohol/drug use; accounting for 
$12.36 \%$ of the variance) and emotion/support coping (including instrumental and emotional support, and ventilation; accounting for $12.18 \%$ of the variance). ${ }^{1}$ Coping subscales showed modest internal reliability levels, .65, .64 and .58 for problem-focused, emotion/support and avoidance coping, respectively.

\section{Media Exposure Inventory}

This instrument was developed for the present study to assess the frequency of use of various media: radio, TV, Internet, SMS, newspapers, and rumors. For each type of media, frequency of use was assessed using a 1-5 ( $1=$ never $; 5=$ always $)$ scale in three separate conditions: everyday updating, leisure time, and following a terror act in Israel. The content validity of the inventory was assessed by two trauma experts. As shown in Table 1, the internal reliability of the three media exposure types was in the range of $.54-.57 .^{2}$

\section{Exposure to a Terror Act}

Respondents were asked to cite the terror event occurring in Israel during the preceding four years that affected them the most, from a list of examples of the most widespread types of acts (e.g., major terror acts occurring in restaurants, buses, hotels, etc.). Actual exposure to the terror act was evaluated by the following self-report question: "Please select and mark an item listed below that best describes your involvement in this event." The items were: (a) I was injured in the terror event; (b) I witnessed the terror event in person, i.e., not through the media; (c) I had significant others (family members or close friends) who were killed during the terror act; (d) I had significant others (family members or close friends) who were injured during the terror act; (e) I had significant others who witnessed the terror event and shared its details with me; and (f) I was not involved in any way in the event. Respondents could mark more than one answer, but it was their first marked category that counted (there were few additional answers).

${ }^{1}$ The two additional factors were not used to derive coping subscales because of the relatively low intercorrelations between the coping strategies that showed high loadings on each factor.

${ }^{2}$ It should be noted that a high level of reliability is not always expected when dealing with the frequency of several events or actions that are not necessarily related. 


\section{Posttraumatic Symptoms}

The study used the Posttraumatic Symptom Scale-Self-Report (PSS-SR; Foa, Riggs, Dancu, \& Rothbaum, 1993), which is the self-report version of the structured interview. It includes 17 items which directly correspond to Diagnostic and Statistical Manual of Mental Disorders (4th ed.; DSM-IV; APA, 1994) symptoms. Symptom frequency over the preceding two weeks is reported on a 4-point scale $(0=$ did not occur or occurred only once; $3=$ occurred five times or more per week or almost all the time). The respondents were asked to refer to the terror act that most shocked them, and to refer to their feelings one week after that event in rating the symptoms. The inventory contains three subscales: reexperiencing ( 5 items), avoidance ( 7 items), and arousal (5 items). Foa et al. (1993) reported an alpha score of .91 and a 1 -month test-retest reliability of .74 for the total score. The Hebrew translation (Gil, 2005) showed high reliability levels for the total scale (.88-.91) and in the present study (.91).

\section{Brief Symptom Inventory (BSI)}

This self-report symptom scale is designed to assess levels of psychopathology (Derogatis \& Melisaratos, 1983). The original scale consists of 53 items describing a variety of problems and complaints (e.g., nervousness, feeling lonely, feeling strain, etc.), originally rated on a $0-3$ scale. The alpha coefficients for all nine dimensions of the BSI range from .71-.85. The Hebrew translation (Gilbar \& Ben-Zur, 2002a, 2002b) showed high internal reliability for each of these scales $(\alpha=.75-.83)$, and for the total $(\alpha=.96)$. The present study used the anxiety, depression, and somatization scales (18 items; the suicidal thoughts item was deleted) from the BSI. Respondents were instructed to refer to their feelings during the occurrence of a terror act in Israel, and rate them on a $0-4$ scale $(0=$ not at all, $4=$ a lot $; \alpha=.94)$, with high score indicating a high level of distress.

\section{RESULTS}

The means of the use of media types for everyday updating, leisure time, and following a terror act in Israel are presented in Table 2. As can be seen in the table the medium most frequently used after a terror act was TV. The intercorrelations of the three media frequency measures were in the range of $.52-.66(p<.001$; see Table 3$)$. 
Table 2. Means of Differential Uses of the Various Media Types

\begin{tabular}{lcccccc}
\hline Type Use & Radio & TV & Internet & SMS & Newspapers & Rumor \\
\hline Updating & 3.29 & 3.82 & 3.82 & 3.24 & 3.18 & 3.62 \\
Leisure & 3.19 & 3.87 & 3.68 & 2.91 & 2.81 & - \\
Terror & 3.31 & 4.50 & 3.53 & 2.46 & 3.42 & 3.66 \\
\hline
\end{tabular}

The distribution of responses regarding each of the six types of exposure to a terror event was as follows: Three $(1.5 \%)$ respondents reported being injured, 11 (5.5\%) witnessed the incident in person, 25 (12.5\%) had significant others who were killed in the event, $8(4.0 \%)$ had significant others who were injured, $21(10.5 \%)$ had significant others who witnessed the event and shared the details with them, and $132(66 \%)$ were not involved in any way. Because the number of respondents in each of the first five categories was small, for the purpose of statistical analysis these five types of exposure were merged into three categories (Gil \& Caspi, 2006) based on similar characteristics: personal exposure, defined as being injured in the event or witnessing it in person, reported by 14 participants (7\%); significant other's exposure, defined as having had significant others who were killed or injured in the event, reported by 33 participants $(16.5 \%)$; and indirect exposure, defined as a report by significant others who witnessed the event and shared its details with the respondent, reported by 21 participants $(10.5 \%)$. No differences were found between the three categories on the BSI or PSS-SR measures, and they were therefore combined, with subsequent analyses using a dichotomous variable of exposure: exposure (1) and no exposure (0).

Table 3 presents the intercorrelations between the study variables. As can be seen in the table, optimism and mastery were highly correlated, and also showed similar positive associations with problem-focused coping and similar negative associations with avoidance coping and the distress and trauma outcomes (i.e., BSI and PSS-SR scores). An index of resources was therefore

Table 3. Intercorrelations of Psychological Variables

\begin{tabular}{|c|c|c|c|c|c|c|c|c|c|}
\hline Variable & 2 & 3 & 4 & 5 & 6 & 7 & 8 & 9 & 10 \\
\hline 1. Mastery & $.54^{* *}$ & $.22^{* * *}$ & -.13 & $-.46^{* * *}$ & .10 & .04 & -.02 & $-.23^{* *}$ & $-.22^{* *}$ \\
\hline 2. Optimism & & $.19^{* * *}$ & .02 & $-.25^{* * *}$ & .11 & .07 & .04 & $-.27^{* * *}$ & $-.19^{* *}$ \\
\hline 3. Problem-focused coping & & & -.03 & $-.20^{* * *}$ & .08 & .06 & $.14^{*}$ & .01 & -.08 \\
\hline 4. Emotion/support coping & & & & $.14^{*}$ & .08 & .02 & .10 & -.00 & .07 \\
\hline 5. Avoidance coping & & & & & .09 & .03 & .09 & $.20^{* *}$ & $.28^{* *}$ \\
\hline 6. Media-terror & & & & & & $.64^{* * *}$ & $.52^{* * *}$ & $.16^{*}$ & $.21^{* *}$ \\
\hline 7. Media-updating & & & & & & & $.66^{* *}$ & .10 & .13 \\
\hline 8. Media-leisure & & & & & & & & .00 & .10 \\
\hline 9. PSS-SR & & & & & & & & & $.57^{* *}$ \\
\hline 10. BSI & & & & & & & & & - \\
\hline
\end{tabular}

Note. $\quad$ PSS-SR = Post-Traumatic Stress Symptoms-Self-Report; BSI = Brief Symptom Inventory.

${ }^{*} p<.05 .{ }^{* *} p<.01$. 
created based on the mean of their $z$-score transformations, following BenZur (2008). The table also shows that media exposure following a terror act was positively correlated with the BSI and PSS-SR outcomes, whereas exposure to the media either to update or for leisure was not correlated with either outcome.

Next, hierarchical regressions were conducted on the PSS-SR and BSI using the demographic variables of gender $(0=$ men, $1=$ women $)$, age, religion $(0=$ Jewish, $1=$ other religions $)$, country of birth $(0=I$ srael, $1=$ other countries $)$, and economic status $(1=b a d, 6=$ excellent $)$ as control variables, entered at Step 1. Exposure to terror events and resource variables were entered at Step 2, coping subscales at Step 3 and the three media exposure types at Step 4. As can be seen in Table 4, and confirming H1, media exposure to terror is related positively to both PSS-SR and BSI after all study and control variables are entered into the regressions. Of the coping styles, only avoidance coping contributed to higher levels of BSI, with no effects found for emotion/support or problem-focused coping, thus only partially confirming $\mathrm{H} 2$, and $\mathrm{H} 3$ was not substantiated. Resources led to lower PSS-SR only, thus only partially supporting H4. Lastly, exposure to terror events contributed positively to both PSS-SR and BSI outcomes, as hypothesized in H5. Apart from these outcomes, the contribution of the demographic variables to the PSS-SR was a nonsignificant $5 \%$, but to the BSI, their contribution was more substantial (20\%): Women, immigrants and non-Jews were in greater distress. In summary, the study variables contributed $15 \%$ and $13 \%$ to the PSS-SR and BSI, respectively, with exposure to terror acts and to the media being more prominent and consistent in contributing to outcomes than resources or avoidance coping, which did contribute to either lower BSI, or higher PSS-SR, respectively.

\section{DISCUSSION}

The main finding of the study is the positive association observed between frequency of exposure to reports of terror in the media and higher levels of posttraumatic symptoms and distress symptoms, as hypothesized. These results were obtained while controlling for all other variables in the study, namely, coping, resources, demographics, and direct exposure-the last revealing a positive association with both posttraumatic and distress outcomes as well. Thus, exposure to terror, either directly or through the media, was shown to be the most potent variable in the study. Media effects on posttraumatic symptoms are in accord with a variety of studies showing the effects of the exposure to media on PTSD in a range of contexts (e.g., Dougall et al., 2005; Schuster et al., 2001; Slone et al., 2008). 


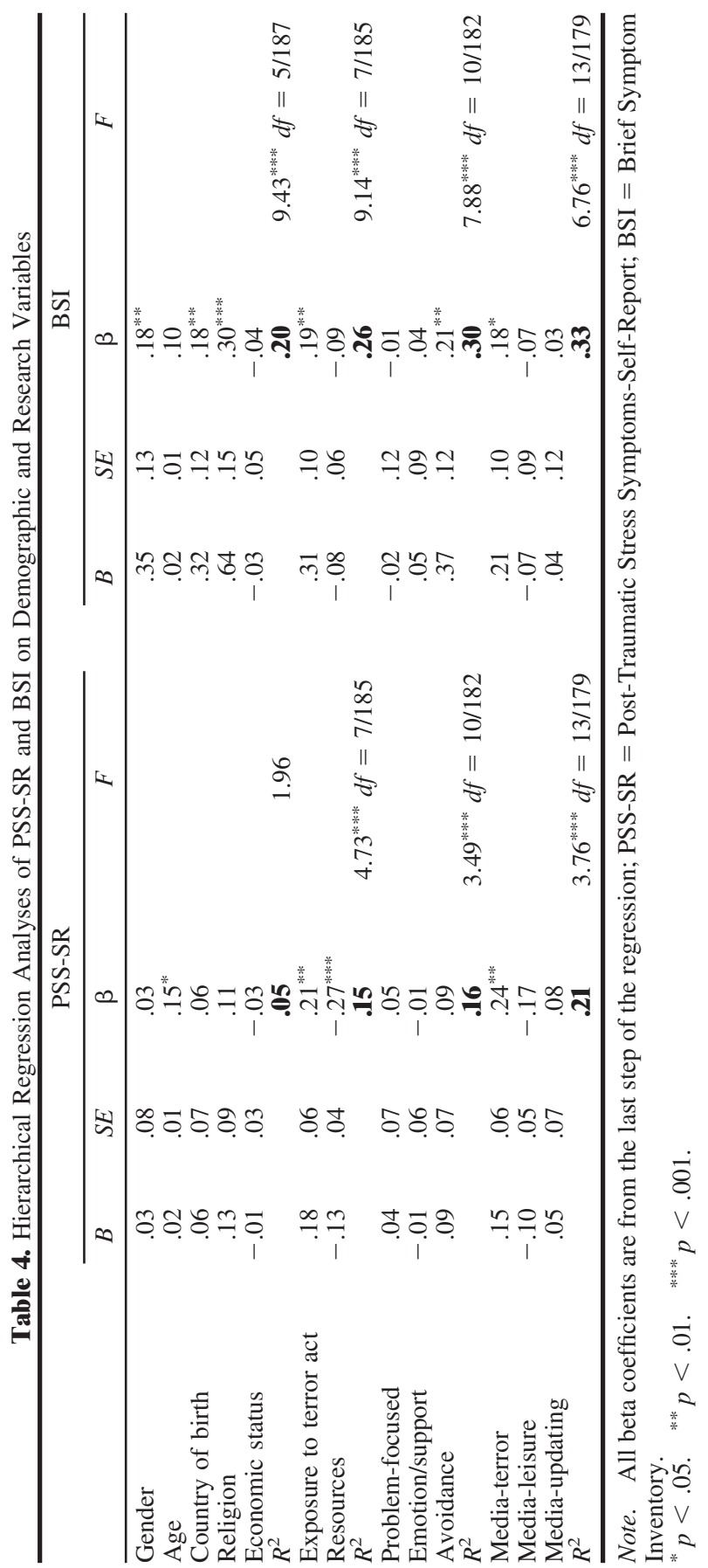


Exposure to terror through the media is in many cases a voluntary act. People usually decide whether or not to watch TV news and special reports on terrorist acts, or to seek specific information about terror acts on the Internet. It should be noted, however, that exposure to terror through the media may also occur involuntarily when changing TV stations randomly or searching the Internet for certain (other than terror) information. Nevertheless, exposure to the media is frequently self-selected, in contrast to the accidental presence in the vicinity where a terrorist act occurs. Moreover, of the various media formats (i.e., radio, TV, Internet, SMS, and newspapers), $\mathrm{TV}$ was rated as the most extensively used medium for acquiring information about terror acts, even in this study sample which was composed of a young population. This means of communication, therefore, is still the most important and presumably the most influential in conveying messages to large sectors of the public, thereby exposing them to frightening images that can contribute to secondary traumatization.

Contrary to the study hypotheses, problem-focused and emotion/support coping were not related to outcomes, as has been found in the context of stressful events (e.g., Penley et al., 2002). Of the coping strategies, only avoidance coping contributed to higher distress levels. This accords with other studies of coping with terror acts, which showed avoidance coping to be related to PTSD (e.g., Gil \& Caspi, 2006), as well as with studies showing avoidance coping to be related to higher levels of anxiety or negative affect in other contexts (e.g., Ben-Zur, 1999, 2002a). Thus, even in a situation of uncontrollable and unpredictable traumatic events such as terror attacks, avoidance coping proves to be a detrimental coping response. In the present study, coping styles rather than situational coping were measured. Thus, although the study is cross-sectional, the use of a trait measure of coping in relation to a terror event lends support to the contribution of avoidance coping to high distress levels.

In accordance with the hypotheses posited, combined resources, namely optimism and mastery, were negatively associated with posttraumatic symptoms, as found in other studies of community disasters (e.g., Ben-Zur, 2008; Benight et al., 1999; Sumer et al., 2005) and of individually experienced stressful events (e.g., Ben-Zur \& Debi, 2005; Epping-Jordan et al., 1999; Helgeson, 1999; Major et al., 1998; Scheier \& Carver, 1992). These data are valuable in suggesting that problem-focused coping generally does not relate to reactions to terror acts, but resources do. This difference in results may be due to the fact that problem-focused coping involves active steps and behaviors that a person may or may not initiate to deal with the stressful encounter, depending on his or her resources and on the situational aspects of ambiguity and control; whereas optimism and mastery are sets of cognitions or beliefs that may be adopted to help people adjust to any situation. 
A number of methodological limitations should be mentioned. First, the study was conducted retrospectively, at a single time point, so that all cause and effect relationships are hypothetical. Arguably, not only does media exposure affect people's symptoms, but that people who suffer from high levels of distress and posttraumatic symptoms may be more prone to expose themselves to media coverage of terror acts.

Furthermore, the study was limited to a specific population-young college students. Indeed, this population was intentionally targeted on the assumption that students are intensive consumers of the largest variety of media. However, using this specific population makes generalizations to other populations limited.

Despite these limitations, the findings support the hypothesis that exposure to terror through the media affects the likelihood of secondary traumatization and mental distress symptoms. These results demonstrate the importance of an awareness of the risks of vicarious exposure to terror and trauma through the media. The study results imply that individual and group therapy methods should be developed for people who were vicariously exposed to terror. Further recommendations are to reduce media coverage of shocking images following terror events, which may affect the likelihood of secondary traumatization and mental distress symptoms. Additionally, the general public should be informed about the risks involved in vicarious exposure to terror through the media. These results also strengthen the notion that people should be encouraged to adopt optimistic and controllable beliefs about themselves and their environments.

\section{REFERENCES}

American Psychiatric Association. (1994). Diagnostic and Statistical Manual of Mental Disorders (4th ed.). Washington, DC: Author.

Baggett, H. L., Saab, P. G., \& Carver, C. S. (1996). Appraisal, coping, task performance, and cardiovascular responses during the evaluated speaking task. Personality and Social Psychology Bulletin, 22, 483-494. doi:10.1177/0146167296225006

Benight, C. C., Swift, E., Sanger, J., Smith, A., \& Zeppelin, D. (1999). Coping self-efficacy as a mediator of distress following a natural disaster. Journal of Applied Social Psychology, 29, 2443-2464. doi:10.1111/j.1559-1816.1999.tb00120.x

Ben-Zur, H. (1999). The effectiveness of coping meta-strategies: Perceived efficiency, emotional correlates and cognitive performance. Personality and Individual Differences, 26, 923-939. doi:10.1016/S0191-8869(98)00198-6

Ben-Zur, H. (2002a). Monitoring/blunting and social support: Associations with coping and affect. International Journal of Stress Management, 9, 357-373. doi:10.1023/A: 1019990518144

Ben-Zur, H. (2002b). Coping, affect and aging: The roles of mastery and self-esteem. Personality and Individual Differences, 32, 357-372. doi:10.1016/S01918869(01)00031-9 
Ben-Zur, H. (2003). Happy adolescents: Subjective well-being, internal resources, and parental factors. Journal of Youth and Adolescence, 32, 67-79. doi:10.1023/A:1021864432505

Ben-Zur, H. (2008). Personal resources of mastery-optimism, and communal support beliefs, as predictors of posttraumatic stress in uprooted Israelis. Anxiety, Stress and Coping: An International Journal, 21, 295-307. doi:10.1080/10615800801956177

Ben-Zur, H., \& Almog, N. (in press). Posttraumatic symptoms and future orientation among Israeli adolescents two years after the second Lebanese war: The effects of war exposure, threat and coping appraisals Journal of Child \& Adolescent Trauma.

Ben-Zur, H., \& Debi, Z. (2005). Optimism, social comparisons and coping with vision loss in Israel. Journal of Visual Impairment and Blindness, 99, 151-164.

Ben-Zur, H., Gilbar, O., \& Lev, S. (2001). Coping with breast cancer: Patient, spouse and dyadic models. Psychosomatic Medicine, 63, 32-39.

Ben-Zur, H., \& Zeidner, M. (1995). Coping patterns and affective reactions under community crisis and daily routine conditions. Anxiety, Stress and Coping, 8, 185-201. doi:10.1080/ 10615809508249372

Bogen, K. T., \& Jones, E. D. (2006). Risks of mortality and morbidity from worldwide terrorism: 1968-2004. Risk Analysis, 26, 45-59. doi:10.1111/j.1539-6924.2006.00706.x

Bonanno, G. A., Galea, S., Bucciarelli, A., \& Vlahov, D. (2006). Psychological resilience after disaster: New York City in the aftermath of the September 11th terrorist attack. Psychological Science, 17, 181-186. doi:10.1111/j.1467-9280.2006.01682.x

Carver, C. S., \& Scheier, M. F. (1993). Vigilant and avoidant coping in two patient groups. In H. W. Krohne (Ed.), Attention and avoidance (pp. 295-319). Seattle, WA: Hogrefe \& Huber.

Carver, C. S., \& Scheier, M. F. (2000). On the structure of behavioral self-regulation. In M. Boekaerts, P. R. Pintrich \& M. Zeidner (Eds.), Handbook of self-regulation (pp. 41-84). New York, NY: Academic Press.

Carver, C. S., Scheier, M. F., \& Weintraub, J. K. (1989). Assessing coping strategies: A theoretically based approach. Journal of Personality and Social Psychology, 56, 267-283. doi:10.1037/0022-3514.56.2.267

Collimore, K. C., McCabe, R. E., Carleton, R. N., \& Asmundson, G. J. G. (2008). Media exposure and dimensions of anxiety sensitivity: Differential associations with PTSD symptom clusters. Journal of Anxiety Disorders, 22, 1021-1028. doi:10.1016/ j.janxdis.2007.11.002

Derogatis, L. R., \& Melisaratos, N. (1983). The Brief Symptom Inventory: An introductory report. Psychological Medicine, 13, 595-605. doi:10.1017/S0033291700048017

Dougall, A. L., Hayward, M. C., \& Baum, A. (2005). Media exposure to bioterrorism: Stress and the anthrax attacks. Psychiatry, 68, 28-42. doi:10.1521/psyc.68.1.28.64188

Ennis, N., Hobfoll, S. E., \& Schroder, K. E. E. (2000). Money doesn't talk, it swears: How economic stress and resistance resources impact inner-city women's depressive mood. American Journal of Community Psychology, 28, 149-173. doi:10.1023/A: 1005183100610

Epping-Jordan, J. E., Compas, B. E., Osowiecki, D. M., Oppedisano, G., Gerhardt, C., Primo, K., \& Krag, D. N. (1999). Psychological adjustment in breast cancer: Processes of emotional distress. Health Psychology, 18, 315-326. doi:10.1037/0278-6133.18.4.315

Figley, C. R. (1995). Compassion fatigue as secondary traumatic stress disorder: An overview. In C. R. Figley (Ed.), Compassion fatigue: Coping with secondary traumatic stress disorder in those who treat the traumatized. New York, NY: Brunner/Mazel.

Foa, E. B., Riggs, D. S., Dancu, C. V., \& Rothbaum, B. O. (1993). Reliability and validity of a brief instrument for assessing post-traumatic stress disorder. Journal of Traumatic Stress, 5, 441-454. doi:10.1002/jts.2490060405.

Galea, S., Nandi, A., \& Vlahov, D. (2005). The epidemiology of post-traumatic stress disorder after disasters. Epidemiologic Review, 27, 78-91. doi:10.1093/epirev/mxi003 
Gelkopf, M., Berger, R., Bleich, A., \& Silver, R. C. (in press). Protective factors and predictors of vulnerability to chronic stress: A comparative study of 4 communities after 7 years of continuous rocket fire. Social Sciences \& Medicine. doi:10.1016/j.socscimed.2011.10.022

Gelkopf, M., Solomon, Z., Berger, R., \& Bleich, A. (2008). The mental health impact of terrorism in Israel: A repeat cross-sectional study of Arabs and Jews. Acta Psychiatrica Scandinavica, 117, 369-380. doi:10.1111/j.1600-0447.2008.01164.x

Gidron, Y., Gal, R., \& Zahavi, S. (1999). Bus commuters' coping strategies and anxiety from terrorism: An example of the Israeli experience. Journal of Traumatic Stress, 12, 185 192. doi:10.1023/A:1024762819880

Gil, S. (2005). Coping style in predicting posttraumatic stress disorder among Israeli students. Anxiety, Stress, and Coping: An International Journal, 18, 351-359. doi:10.1080/ 10615800500392732

Gil, S., \& Caspi, Y. (2006). Personality traits, coping styles, and perceived threat as predictors of posttraumatic stress disorder after exposure to a terrorist attack: A prospective study. Psychosomatic Medicine, 68, 904-909. doi:10.1097/01.psy.0000242124.21796.f8

Gilbar, O., \& Ben-Zur, H. (2002a). Cancer and the family caregiver: Distress and coping. Springfield, IL: Charles C. Thomas.

Gilbar, O., \& Ben-Zur, H. (2002b). Bereavement of spouse caregivers of cancer patients. American Journal of Orthopsychiatry, 72, 422-432. doi:10.1037/0002-9432.72.3.422

Helgeson, V. C. (1999). Applicability of cognitive adaptation theory to predicting adjustment to heart disease after coronary angioplasty. Health Psychology, 18, 561-569. doi:10.1037/ $0278-6133.18 .6 .561$

Hobfoll, S. E. (1989). Conservation of resources: A new attempt at conceptualizing stress. American Psychologist, 44, 13-524. doi:10.1037/0003-066X.44.3.513

Hobfoll, S. E. (1991). Traumatic stress: A theory based on rapid loss of resources. Anxiety Research, 4, 187-197. doi:10.1080/08917779108248773

Hobfoll, S. E. (2001). The influence of culture, community, and the nested-self in the stress process: Advancing conservation of resources theory. Applied Psychology: An International Review, 50, 337-421. doi:10.1111/1464-0597.00062

Hobfoll, S. E., Jackson, A., Hobfoll, I., Pierce, C. A., \& Young, S. (2002). The impact of communal mastery versus self-mastery on emotional outcomes during stressful conditions: A prospective study of Native American women. American Journal of Community Psychology, 30, 853-871. doi:10.1023/A:1020209220214

Hobfoll, S. E., \& Walfisch, S. (1984). Coping with a threat to life: A longitudinal study of self-concept, social support, and psychological distress. American Journal of Community Psychology, 12, 87-100. doi:10.1007/BF00896930

Keinan, G., Sadeh, A., \& Rosen, S. (2003). Attitude and reactions to media coverage of terrorist acts. Journal of Community Psychology, 31, 149-165. doi:10.1002/jcop.10040

Krohne, H. W. (1993). Vigilance and cognitive avoidance as concepts in coping research. In H. W. Krohne (Ed.), Attention and avoidance: Strategies in coping with aversiveness (pp. 19-50). Seattle, WA: Hogrefe \& Huber.

Lazarus, R. S. (1999). Stress and emotion: A new synthesis. London, UK: Free Association Books.

Lazarus, R. S., \& Folkman, S. (1984). Stress, appraisal and coping. New York, NY: SpringerVerlag.

Liverant, G. I., Hofmann, S. G., \& Litz, B. T. (2004). Coping and anxiety in college students after the September 11th terrorist attacks. Anxiety, Stress, and Coping: An International Journal, 17, 127-139. doi:10.1080/0003379042000221412

Maguen, S., Papa, A., \& Litz, B. T. (2008). Coping with the threat of terrorism: A review. Anxiety, Stress, \& Coping, 21, 15-35. doi:10.1080/10615800701652777

Major, B., Richards, C., Cooper, M. L., Cozzarelli, C., \& Zubek, J. (1998). Personal resilience, 
cognitive appraisals, and coping: An integrative model of adjustment to abortion. Journal of Personality and Social Psychology, 74, 735-752. doi:10.1037/0022-3514.74.3.735

McCann, I. L., \& Pearlman, L. A. (1990). Vicarious traumatization: A framework for understanding the psychological effects of working with victims. Journal of Traumatic Stress, 3, 131-149. doi:10.1007/BF00975140

Miller, S. M., Combs, C., \& Kruus, L. (1993). Tuning in and tuning out: Confronting the effects of confrontation. In H. W. Krohne (Ed.), Attention and avoidance: Strategies in coping with aversiveness (pp. 51-69). Seattle, WA: Hogrefe \& Huber.

Moos, R. H., \& Schaefer, J. A. (1993). Coping resources and processes: Current concepts and measures (pp. 234-257). In L. Goldberger \& S. Breznitz (Eds.), Handbook of stress: Theoretical and clinical aspects (2nd ed.). New York, NY: The Free Press.

Nacos, B. L. (2007). Mass-mediated terrorism: The central role of the media in terrorism and counterterrorism (2nd. ed.). Lanham, MD: Rowman \& Littlefield.

Nes, L. S., \& Segerstrom, S. C. (2006). Dispositional optimism and coping: A meta-analytic review. Personality and Social Psychology Review, 10, 235-251. doi:10.1207/ s15327957pspr1003_3

Norris, F. H., Friedman, M. J., Watson, P. J., Byrne, C. M., Diaz, E., \& Kaniasty, K. (2002). 60,000 disaster victims speak: Part I. An empirical review of the empirical literature, 1981-2001. Psychiatry, 65, 207-239.

Palmieri, P. A., Canetti-Nisim, D., Galea, S., Johnson, R. J., \& Hobfoll, S. E. (2008). The psychological impact of the Israel-Hezbollah War on Jews and Arabs in Israel: The impact of risk and resilience factors. Social Sciences \& Medicine, 67, 1208-1216. doi:10.1016/j.socscimed.2008.06.030

Pearlin, L. I. (1999). Stress and mental health: A conceptual overview. In A. V. Horwitz \& T. L. Scheid (Eds.), A handbook for the study of mental health: Social contexts, theories and systems (pp. 161-175). Cambridge, UK: Cambridge University Press.

Pearlin, L. I., \& Schooler, C. (1978). The structure of coping. Journal of Health and Social Behavior, 19, 2-21. doi:10.2307/2136319

Pearlman, L. A., \& Saakvitne, K. W. (1995). Trauma and the therapist: Countertransference and vicarious traumatization in psychotherapy with incest survivors. New York, NY: W. W. Norton.

Penley, J. A., Tomaka, J., \& Wiebe, J. S. (2002). The association of coping to physical and psychological health outcomes: A meta-analytic review. Journal of Behavioral Medicine, 25, 551-603. doi:10.1023/A:1020641400589

Scheier, M. F., \& Carver, C. S. (1985). Optimism, coping and health: Assessment and implications of generalized outcome expectancies. Health Psychology, 4, 219-247. doi: 10.1037/0278-6133.4.3.219

Schuster, M. A., Stein, B. D., Jaycox, L. H., Collins, R. L., Marshall, G. N., Elliott, M. N., .. . Berry, S. H. (2001). A national survey of stress reactions after the September 11, 2001 terrorist attacks. New England Journal of Medicine, 345, 1507-1512.

Skinner, E. A., Edge, K., Altman, J., \& Sherwood, H. (2003). Searching for the structure of coping: A review and critique of category systems for classifying ways of coping. Psychological Bulletin, 129, 216-269. doi:10.1037/0033-2909.129.2.216

Slone, M. (2000). Responses to media coverage of terrorism. Journal of Conflict Resolution, 44, $508-523$.

Slone, M., \& Shoshani, A. (2010). Prevention rather than cure? Primary or secondary intervention for dealing with media exposure to terrorism. Journal of Counseling \& Development, 88, 440-448.

Slone, M., Shoshani, A., \& Baumgarten-Katz, I. (2008). The relation between actual exposure to political violence and preparatory intervention for exposure to media coverage of terrorism. Anxiety, Stress and Coping: An International Journal, 21, 243-261. doi: $10.1080 / 10615800701510124$

Sumer, N., Karanci, A. N., Berument, S. K., \& Gunes, H. (2005). Personal resources, coping 
self-efficacy, and quake exposure as predictors of psychological distress following the 1999 earthquake in Turkey. Journal of Traumatic Stress, 18, 331-342. doi:10.1002/ jts. 20032

Swenson, D. X., \& Johnson, G. H. (2003). A college community's vicarious stress reaction to September 11th terrorism. Traumatology, 9, 93-105. doi:10.1177/153476560300900203

Teo, T. S. H., \& Heong Pok, S. (2003). Adoption of the Internet and WAP-enabled phones in Singapore. Behavior \& Information Technology, 22, 281-289. doi:10.1080/ 0144929031000119385

Terry, D. J. (1994). Determinants of coping: The role of stable and situational factors. Journal of Personality and Social Psychology, 66, 895-910. doi:10.1037/0022-3514.66.5.895

Thompson, S. C., Schlehofer, M. M., Bovin, M. J., Dougan, B. T., Montes, D., \& Trifskin, S. (2006). Dispositions, control strategies, and distress in the general public after the 2001 terrorist attack. Anxiety, Stress and Coping, 19, 143-159. doi:10.1080/ 10615800600615891

Wilkinson, P. (1997). The media and terrorism: A reassessment. Terrorism and Political Violence, 9, 53-64.

Zeidner, M. (1995). Coping with examination stress: Resources, strategies, outcomes. Anxiety, Stress and Coping, 8, 279-298. doi:10.1080/10615809508249379

Zeidner, M. (2007). Anxiety and coping with community disasters: The Israeli experience. Journal of Research in Personality, 41, 213-220. doi:10.1016/j.jrp.2006.02.002

Zeidner, M., \& Ben-Zur, H. (1993). Coping with a national crisis: The Israeli experience with the threat of missile attacks. Personality and Individual Differences, 14, 209-224. doi:10.1016/0191-8869(93)90191-5

Zeidner, M., \& Ben-Zur, H. (1994). Individual differences in anxiety, coping, and posttraumatic stress in the aftermath of the Persian Gulf war. Personality and Individual Differences, 16, 459-476. doi:10.1016/0191-8869(94)90072-8

Received September 11, 2011

Revision received February 21, 2012

Accepted February 23, 2012 